\title{
Studies on Intestinal Helminthes infection in Rumde Nursery and Primary School Pupils, in Jimeta, Adamawa State, Nigeria
}

\author{
${ }^{* 1}$ R.S. Naphtali, ${ }^{2}$ Y.M. Birdling ${ }^{1}$ B. Philimon \\ ${ }^{1 .}$ Department of Zoology, Modibbo Adama University of Technology, Yola. Nigeria \\ 2. Department of Biology, School of Sciences Adamawa State, College of Education Hong Nigeria
}

\begin{abstract}
A study on prevalence of intestinal helminthes among nursery and primary school pupils was conducted in Rumde, Jimeta, Adamawa State, Nigeria. The study was aimed at determining the intestinal helminthes in relation to sex, age, parent occupation and socio-economic factors among the pupils. A crosssectional study involving 144 pupils were involved where questionnaire was given to assess the socio-economic factors. Stool specimens were examined using the formal ether concentration technique. Chi-square was used for the data analysis at $(p<0.05)$ level of significance. Out of the total sample population, 26(18.1\%) were helminth infected. Six helminthes parasite species were encountered during the study. Ascaris lumbricoides had the highest prevalence rate of $42.3 \%$ closely followed by Hookworm, 32.7\%, while Schistosoma mansoni, 1.9\% had the lowest. Pupils between age group 0-6 years had the highest infection rate of 40.0\% and the lowest infection was observed among those within age bracket 13-15 years, 31.2\%, while others were 7-9 years, $33.3 \%, 10-12$ years, $37.9 \%$. The study showed a significant relationship between infection and parents occupation, as 59.0\% was recorded among traders as the highest occurrence and $42.3 \%$ among Civil servant as the lowest cases recorded with statistical significant different at $p<0.05$. Table 4. Showed that, pupils using bush had 50.0\% infection rate as the highest cases, while those using water closet and bush had $0.0 \%$ infection rate with statistical significant difference at $p<0.05$.
\end{abstract}

Keywords: Adamawa, intestinal helminthes, infection, nursery and primary, Nigeria

\section{Introduction}

Parasitic infection, particularly intestinal helminthes cause hundreds of thousands of avoidable deaths each year, and is among the Wolds most common infectious disease Girum, (2005). Intestinal parasites are highly prevalent causing serious health problems in the tropics. Schoolchildren carried the highest borden of morbidity due to intestinal helminthes and schistosomes infections (Timothy et al., 2013). The public health significance of schistosomes and geohelminthes continued because of their high prevalence and effect on human, particularly those living in the tropical and subtropical region Lekun, (2001).

Intestinal helminthes has become a major problem in rural settlements in Nigeria. This is as a result of poor socio- economic status and lack of basic amenities such as pipe borne water and other sanitary facilities (Okon and Okun, 2001). They also have detrimental effects on animal survival (Silva et al., 1996). In Nigeria as in most part of the developing World, the dominant pathogens are parasitic and infectious diseases (Amuga et al., 2006). According to the World Health Organization (WHO. 1998, and Obukwu, et al., 2008) globally, there are 800-1,000 million cases of ascariasis, 700-900 million hookworm infections, 500 million cases of trichuriasis and majority are in children and women of childbearing age these infections are easily contracted through drinking and eating of undercook/un-boiled faecal contaminated food and water (Okolie, 2009). Mwanhi, et al. (2008) reported that worm infections are common in childhood condition in most developing Countries because of their high morbidity and low hygiene standard. Pupils are particularly vulnerable to these parasites (Montosore et al., 2002).

\subsection{Materials and Methods}

A cross-sectional study was conducted among 144 schoolchildren in Rumde town which is located in Jimeta, Yola-North Local Government Area of Adamawa State. The study Area lies between longitude $10^{\circ} \mathrm{E}$ and latitude $13^{\circ} \mathrm{E}$ and longitude $15^{\circ} \mathrm{N} 12^{\circ} \mathrm{N}$ which is situated in the North-Eastern part of Nigeria (Umaru et al., 2007).

\subsubsection{Faecal Sample collection}

A well labeled wide-mouthed sample bottles were given to the selected pupils for the study and were instructed on how to collect their faecal sample without contamination, the faecal samples were immediately preserved with $10 \%$ formalin solution and were taken to laboratory for analysis. 


\subsubsection{Questionnaire}

A structured Questionnaire was administered to each of the selected pupils which was filled by some of their teachers on interviewing them.

\subsubsection{Laboratory examination of faecal sample}

The faecal sample was examined for presence of parasites using the formaldehyde-ether concentration technique as described by Cheebrough (1992). 1 gram of faecal sample was emulsified in $4 \mathrm{ml}$ of $10 \%$ formaldehyde solution and mixed properly. The suspension was passed through a funnel covered with a guaze pad to remove debris from entering centrifuge tube. $3 \mathrm{ml}$ of ether was added and the suspension was thoroughly mixed, the tube was centrifuge for 3 minutes at 4000rpm and one was put on a plain slide and was observed under microscope usin X10 for observation. Parasites were identified using medical laboratory manual for tropical Countries (second edition) by Cheesbrough (1992).

\subsubsection{Statistical Analysis}

The data obtained in the study are presented in tables; interpretations were made in percentages and analyzed with respect to age, parents' occupation and toilet facilities. Chi-square was used to determine prevalence significance difference among the Pupils.

\section{Results}

In this study, a total of 144 faecal samples from Pupils were examined. Generally, 6 types of helminthes were encountered (table 1) Out of these, 52(36.1\%) were positive with helminthes infection, and, Ascaris lumbricoides had the highest prevalence (42.3\%) while Schistosoma mansoni had the lowest prevalence $(1.9 \%)$ with statistical significance difference $(\mathrm{p}<0.05)$. Pupils ranging from $0-6$ years had the highest infection rate with $40.0 \%$ while the least prevalence is among age group 13-15 years with $31.2 \%$. (table 2).

The prevalence of intestinal helminthes in relation to parents' occupations showed that, all Pupils examined were exposed to intestinal helminthes irrespective of their parents' occupation, but the most vulnerable ones are whose their parents are trader (table 3). Also, children that use bush for defecation had the highest infection rate $(50.0 \%)$ and least among those that used water closet (17.6) table 4.

Table 1: Prevalence of specific intestinal helminthes

\begin{tabular}{|l|l|l|}
\hline helminthes & prevalence & $\%$ infected \\
\hline Ascaris lumbricoides & 22 & 42.3 \\
\hline Hookworm & 17 & 32.7 \\
\hline Strongyloides stercolali & 6 & 11.5 \\
\hline Tania species & 2 & 3.8 \\
\hline Trichuris trichuris & 4 & 7.7 \\
\hline Schistosoma mansoni & 1 & 1.9 \\
\hline Total & 52 & 100.0 \\
\hline
\end{tabular}

Table 2: Prevalence of intestinal helminthes in Relation to age

\begin{tabular}{|l|l|l|l|}
\hline Age group & Number Examined & Number infected & $\%$ infected \\
\hline $0-6$ & 5 & 2 & 40.0 \\
\hline $7-9$ & 36 & 12 & 33.3 \\
\hline $10-12$ & 87 & 33 & 37.9 \\
\hline $13-15$ & 16 & 5 & 31.2 \\
\hline Total & \multicolumn{2}{|c|}{26} & 18.1 \\
\hline
\end{tabular}

Table 3: Prevalence of intestinal helminthes according parent occupation

\begin{tabular}{|c|c|c|c|}
\hline Parent occupation & Number examined & Number infected & \% infected \\
\hline Civil servant & 29 & 14 & 42.3 \\
\hline Trader & 61 & 36 & 59.0 \\
\hline Farmer & 28 & 14 & 50.0 \\
\hline Other & 26 & 15 & 57.6 \\
\hline Total & 144 & 69 & 47.9 \\
\hline
\end{tabular}

Table 4: prevalence of intestinal helminthes in relation to toilet facilities

\begin{tabular}{|l|c|c|c|}
\hline Toilet facilities & No examined & No infected & $\%$ infected \\
\hline Pit & 98 & 36 & 36.7 \\
\hline Bush & 4 & 2 & 50.0 \\
\hline Water closet & 17 & 3 & 17.6 \\
\hline Pit and bush & 23 & 11 & 47.8 \\
\hline Water closet & 2 & 0 & 00.0 \\
Total & 144 & 52 & 36.1 \\
\hline
\end{tabular}




\section{Discussion}

In this study, 6 intestinal helminthes were indentified, this concurs with the work of Shehu, et al, (2013) who reported 5 different intestinal helminthes among schoolchildren in Maru Local Government Area Zamfara State Nigeria. The predominant parasite involved was Ascaris lumbricoides which has $42.3 \%$ prevalence, this finding is in line with the work of (Shehu et al., 2013, Taiwo and Agbolade, 2000 and Adeyeba and Akinlabi, 2002) whose their reports revealed very high prevalence of Ascaris lumbricoides than the rest of the helminthes involved in their studies, while the least species is Schistosoma mansoni (1.9\%) which is contrary to the records of Girum, (2005) who observed 4.3\% cases of Schistosoma mansoni and 3.9\% Ascaris lumbricoides. The differences could be due to poor personal hygiene among the pupils.

Pupils ranging from 0-6 years have the highest prevalence infection of $40.0 \%$ and those between 13-15 years have less prevalence rate with $13.2 \%$. This finding has tally with the results of (Timothy et al., 2013) who recorded $40.5 \%$ among 0-6 years and $11.0 \%$ among 13-15 years respectively. No infection was reported among those using water closet $(0.0 \%)$ and it agreed with the work of (Shehu et al., 2013) who recorded very low infections among pupils that used water closet (1.5\%). This study showed that parents occupation influence infection rate among children. Pupils whose parents are trader were recorded with high infection $(57.0 \%)$ this was similarly observed by Adeyeba and Tijani, (2002). This can be attributed to the facts that the children were always in contact with natural body of water contaminated withfaecal materials. However, this finding disagreed with the work of Akogun, (1998) that was conducted among 2 communities along Benue River valley Adamawa State, where children of civil servant were recorded with high helminthes infection.

\section{Conclusion}

It is well known that intestinal parasitic infections are more common in children. These infections deteriorate the psychological and physical development of the children and various symptoms are associated with it, such as malnutrition, emaciation, abnormal pains, mental backwardness, and poor growth. Some of these features were observed physically among some children and indeed some complained of these symptoms are linked with intestinal parasitic infections.

\section{Recommendations}

In view of the high rate of infections, the following are recommended:

1. There should be regular school-based de-worming programme across the state.

2. There is need to encourage health education for school-aged children as to enable them learn basic hygiene

\section{References}

[1]. Adeyeba, O.A., and Akinlabi, A.M. (2002). Intestinal parasitic infection among schoolchildren in rural community. South West Nieria. The Journal of Parasitology.23: 11-18.

[2]. Adeyeba, O.A. and Tijani, B.D. (2002). Intestinal helminthiasis among malnourished school ae children in peri-urbban Area of Ibadan, Nieria. African Journal of Clinical and Experimental Microbioloy. 3(1) 24-28.

[3]. Amuga, G. Usmand, C.O.E. (2006). Human intestinal parasites amon inmates of Kiffi prison. Nasarawa State. Internation Journal of Natural and Applied Sciences. 2: 7-10.

[4]. Akogun, O.B. and Badaki, J. (1998). Intestinal helminth infection in two communities along Benue river valley, Adamawa State. Nigerian Journal Parasitology. 19: 67-72.

[5]. Cheesbrough, M.(1992). District practice in tropical Countries, part 1 (second edition) Cambrie University Press, 194-235.

[6]. Girum, T. (2005). The prevalence of intestinal helminthic infections and associated risk factors among school children in Babile town, Eastern Ethiopia. Ethiopian Journal of Health and Development 19(2): 140-147.

[7]. Lekun, J. (2001). Soil transmitted helminth infections and Schistosoma mansoni in school children from Chilga District, Northwest Ethiopia. Ethiopian Journal of Health Science 11(2): 79-87.

[8]. Montresor, A., Crompton, D.W.T., Gyorkos, T.W. and Savioli, L. (2002). Helminth control in school-age children: A guide for managers of control programme.

[9]. Mwanhi, M.A., Kinsti, M.K., Wamae, A.W., Ndonga, M. and Migiro, P.S. (2008). Prevalence of intestinal worm infections among primary school children in Nairobi City, Kenya. Eastern African Journal of Public Health. 15:86-89.

[10]. Obiukwu, M.O., Umeanaeto, P.U., Eneanya, C.I. and Nwaorgu, G.O. (2008). Prevalence of gastro-intestinal helminthes in school children in Mbaukwu, Adamawa State. Nigeria. Nigerian Journal of Parasitology 29(1): 15-19.

[11]. Okolie, N.J.C. (2009). Intestinal parasites distribution amon inmates of Owerri prison. International Journal of Parasitic Diseases. 4(1):1-4.

[12]. Okon, O. and Oku, E. (2001). Prevalence of intestinal parasites among school children in two contrastin communities in Cross River State, Nigeria. Nigerian Journal of Parasitology. 22: 117

[13]. Taiwo, A.K. and Agbolade, O.M. (2000). Intestinal helminthiasis amon school children in Oru, Ogun State, Nigeria. Nigerian Journal of Sciences. 34: 283-286.

[14]. Timothy, A., Ezekiel, K. and Kokori, A. (2013). Studies on the intestinal helminths infection among primary school children in Gwagwada, Kaduna, North Western Nigeria. Journal of Biology, Agriculture and healthcare. 3(7): 1-6.

[15]. Umaru, N.F., Akogun, O.B. and Owuama, C.I. (2007). Species identification of Anopheles and Culex mosquitoes and its epidemiologyimplication in Yola, Nigeria. Nigerian Journal of parasitology 28(2): 114-117.

[16]. World Health Oranization, (1998). International Parasite Control: Burden and Trends. Document No. WHO/CTD/HTM/98:24. 